
\title{
25 Research Soure \\ Fabrication of thermo-regulating cotton fabric with enhanced flame retardancy via layer-by-layer assembly
}

\section{Yunbo Chen}

Donghua University - Songjiang Campus: Donghua University

\section{Xiangyu Zhu}

Donghua University - Songjiang Campus: Donghua University

\section{Xiang Li}

Donghua University - Songjiang Campus: Donghua University

\section{Bijia Wang}

Donghua University - Songjiang Campus: Donghua University

\section{Zhiping Mao}

Donghua University - Songjiang Campus: Donghua University

\section{Xueling Feng}

Donghua University - Songjiang Campus: Donghua University

Xiaofeng Sui ( $\nabla$ suixf@dhu.edu.cn )

Donghua University https://orcid.org/0000-0001-7446-5765

\section{Hong Xu}

Donghua University - Songjiang Campus: Donghua University

\section{Research Article}

Keywords: Cotton Fabrics, Phase Change Microcapsules, Flame Retardancy, Thermo-regulating, Layer-bylayer Assembly

Posted Date: March 1st, 2021

DOI: https://doi.org/10.21203/rs.3.rs-230002/v1

License: (c) (i) This work is licensed under a Creative Commons Attribution 4.0 International License. Read Full License 


\section{Abstract}

The lack of thermo-regulation functionality and high flammability of cotton fabrics greatly restrict their application in high-performance fields. Herein, we report a versatile layer-by-layer (LbL) assembly strategy for introducing to cotton fabrics a multilayered coating consisted of phase change microcapsules and ammonium polyphosphate, endowing them with thermo-regulating and flame retardancy. The coated fabrics were characterized by limiting oxygen index (LOI), scanning electron microscopy (SEM), thermogravimetry (TG), differential scanning calorimetry (DSC) and infrared thermal imaging. The fabric deposited with 20 bilayers (MCPM/APP-20) showed improved flame retardancy with a LOI of $24.4 \%$ and residual carbon of $34.24 \%$. It also shows a melting enthalpy of $30.16 \mathrm{~J} / \mathrm{g}$, which transferred to a temperature difference of $6.4{ }^{\circ} \mathrm{C}$ compared with pristine cotton. The functional endowed by the LbL assembly was reasonably durable, with melting enthalpy and residual carbon of MPCM/APP-20 reduced to $17.14 \mathrm{~J} / \mathrm{g}$ and $19.82 \%$ after 30 laundering cycles. These results suggest that LbL assembly was a convenient way for functionalization of cotton fabrics.

\section{Introduction}

Cotton is the most important natural substrate for textile and clothing industry because of its excellent wearability and for being bio-degradable and renewable(Fang et al. 2015). Nevertheless, apparels made from plain cotton fabrics cannot provide adequate protection to wearers in specific scenarios such as fire hazards or extreme weather conditions(Masood et al. 2020). Researchers had been working lately to impart thermo-regulating functionality to cotton fabrics by introducing phase change materials (PCMs) (Kumar et al. 2014; Scacchetti et al. 2017; Sun and lqbal 2017).

PCMs are thermal energy storage materials that can absorb and release thermal energy during phase transition (Liu et al. 2020; Ma et al. 2015a; Qiao et al. 2020). However, bulk PCMs transform into liquids at higher temperature which confined their applications(Jin et al. 2013; Wang et al. 2016). This problem could be solved by microencapsulation of phase change materials. Microencapsulated PCMs (MPCM) have a higher heat transfer area per unit volume and tolerate volume changes during phase change processes without their enthalpies being much compromised(Mohaddes et al. 2014; Su et al. 2017; Vitorino et al. 2014; Zhao and Zhang 2011).

MPCM could be conveniently introduced to cotton fabrics using conventional finishing methods(lqbal and Sun 2018; Prajapati and Kandasubramanian 2019; Sun and lqbal 2017). Alay et al(Alay Aksoy et al. 2017). constructed a cotton-based thermal regulating fabric that showed up to $3.1^{\circ} \mathrm{C}$ difference to pristine cotton fabric by incorporating a MPCM via the pad-dry-cure method. Saraç et al.(Saraç et al. 2019) fabricated stretch denim-based and cotton-based thermal regulating fabrics, whose latent heats were $10.1 \mathrm{~J} / \mathrm{g}$ and $14.9 \mathrm{~J} / \mathrm{g}$, respectively, via knife-coating technique. MPCM had also been introduced to fabrics by coating(Su et al. 2020), printing(Sánchez et al. 2010), grafting(Benmoussa et al. 2018), exhaustion(Bonet et al. 2012) and spinning(Iqbal and Sun 2014; Li et al. 2013; Li et al. 2014). However, durability of the thermo-regulating function imparted by these methods was generally poor. 
Moreover, these fabrics became susceptible to fire hazard due to intrinsic flammability of paraffin wax, commonly applied as the phase change core. Using flame-retardant MPCMs is a good approach to conquer this deficiency(Qiu et al. 2015). Demirbağ et al.(Demirbağ and Aksoy 2016) imparted flameretardancy to MPCMs via introducing clay nano-particles (Clay-NPs) into the gelatin/sodium alginate shell, and observed improvement in flame retardancy of finished cotton fabrics (burning time increased from $19.24 \mathrm{~s}$ to $34.48 \mathrm{~s}$ ). Nevertheless, the preparation of flame-retardant MPCMs was complex and the durable property were also unsatisfactory.

Layer-by-Layer ( $\mathrm{LbL}$ ) assembly technique as a facile, versatile and cost-effective strategy had been used to prepare functional fabrics, such as flame retardant(Carosio et al. 2015; Fang et al. 2019), antiultraviolet(Liu et al. 2012; Saini et al. 2020), hydrophobic(Li et al. 2019b; Xue et al. 2020), and antibacterial(Ali et al. 2020; Bashari et al. 2020). In this paper, we introduced MPCM and ammonium polyphosphate onto cotton fabrics via the LbL technique, to improve their thermo-regulating performances and flame retardant properties. The treated fabrics were examined for thermo-regulating performance, flame retardant property, thermal stability and durable properties. The results indicated that highly durable thermo-regulating and flame-retardant cotton fabrics could be obtained by this facile and cost-effective strategy.

\section{Materials And Methods}

Materials

Woven cotton fabrics were supplied by the Luthai Textile Co., Ltd, China., n-octadecane, acetic acid, hydrochloric acid $(\mathrm{HCl})$ and ethanediamine were purchased from Sinopharm Chemical Reagent Co., Ltd, China. Ammonium polyphosphate (APP), isophorone diisocyanateand (IPDI) and sodium hydroxide $(\mathrm{NaOH})$ were provided by Adamas Co., Ltd. Chitosan (high viscosity) was supplied by Macklin Biochemical Co., Ltd, Shanghai. Glycidyltrimethylammonium chloride (CHTAC) was purchased from Energy Chemical Co., Ltd. All chemicals were used as received.

\section{Preparation of MPCM}

Phase change microcapsules were prepared by interfacial polymerization using a procedure modified from our previous report (Zhu et al. 2020). IPDI ( $2.00 \mathrm{~g})$ and n-octadecane $(6.00 \mathrm{~g})$ were mixed in a 100 $\mathrm{mL}$ beak at $60{ }^{\circ} \mathrm{C}$ and used as the oil phase. An aqueous suspension of regenerated nanochitin (RCh, $48.0 \mathrm{~g}, 0.15 \mathrm{wt} \%$ ) was added in as the aqueous phase. A stable Pickering emulsion was obtained by emulsifying the mixture for 3 min using a homogenier ((IKA T18, Germany)) at $9000 \mathrm{rpm}$. Subsequently, the emulsion was stirred at $200 \mathrm{rpm}$ and heated to $70{ }^{\circ} \mathrm{C}$ for 2 hours, after which a solution of ethanediamine ( $27.0 \mathrm{~g}, 2.00 \mathrm{wt} \%$ ) was dropped in. More ethanediamine was added as a more concentrated solution ( $21.6 \mathrm{~g}, 10.0 \mathrm{wt} \%$ ) over a course of 4 hours. Then, stirring was lowered to $100 \mathrm{rpm}$ and the mixture was cooled to ambient temperature. Finally, microcapsules were collected through filtration and dried for 24 hours at ambient temperature. 
Cotton fabric (5.0 g) was impregnated in a mixed solution of $18.8 \mathrm{~g} / \mathrm{L} \mathrm{CHTAC}$ and $9.0 \mathrm{~g} / \mathrm{L} \mathrm{NaOH}$, at a liquor ratio of $1: 30$. The mixture was stirred for $1 \mathrm{~h}$ at $70^{\circ} \mathrm{C}$. Subsequently, the fabric was washed using deionized water and dried in oven at $60{ }^{\circ} \mathrm{C}$ to yield the positively charged cotton fabric.

Preparation of the APP solution and the MPCM solution

APP $(1.5 \mathrm{~g})$ was dissolved in deionized water $(33.5 \mathrm{~g})$. The mixture was stirred until transparent, after which $2 \mathrm{M} \mathrm{NaOH}(7.5 \mathrm{~mL})$ was added. Then, the $\mathrm{pH}$ was adjusted to 10 with $2 \mathrm{M} \mathrm{HCl}$ to obtain the $3.0 \mathrm{wt}$ $\%$ APP solution. Zeta potential of the APP solution was measured and the results showed that a maximum negative potential of $-30.8 \mathrm{mV}$ was recorded at $\mathrm{pH}=10$ (Fig. S1, Supporting Information).

Chitosan $(1.00 \mathrm{~g})$, acetic acid $(1.00 \mathrm{~g})$ and MPCMs $(2.00 \mathrm{~g})$ were combined and added in deionized water $(96.0 \mathrm{~g})$ with stirring to obtain the $2.0 \mathrm{wt} \%$ MPCM solution.

Thermo-regulating and flame-retardant treatment of cotton fabric

The process to impart the thermo-regulating and flame-retardant coating on cotton fabrics is illustrated in Fig. 1. In detail, the positively charged cotton fabrics were successively impregnated in $3.0 \mathrm{wt} \%$ APP solution and $2.0 \mathrm{wt} \%$ MPCM suspension for $10 \mathrm{~min}$, respectively. The samples were dried at $60{ }^{\circ} \mathrm{C}$ after each immersion. By repeating this process in a cyclic manner, multilayered fabrics (MPCM/APP-n) were obtained, where $\mathrm{n}$ represents the cycle number.

\section{Characterizations}

Malvern Zetasizer (Nano-ZS, UK) was used to test the Zeta potential of samples. The measurements were repeated three times. The morphology of MPCMs and the cotton fabrics were characterized by scanning electron microscopy (SEM, TM3030, Hitachi, Japan). Before the test, all the samples were coated with gold. Limiting oxygen index (LOI) of fabrics was determined using an oxygen index testing instrument (5801A, Suzhou Vouch Testing Technology Co., Ltd, China), referring to ASTM D2863 standard. The chemical composition of the treated cotton fabrics was analyzed using FT-IR spectroscopy (PerkingElmer Spectrum-Two, USA) over the wavenumber range from $400-4000 \mathrm{~cm}^{-1}$. Thermogravimetry was performed on a thermal analyzer (TG, 209F1, Netzsch, Germany) to observe the thermal decomposition behavior of MPCMs and cotton fabrics. All samples were heated from $30^{\circ} \mathrm{C}$ to $600{ }^{\circ} \mathrm{C}$ at a heating rate of $10{ }^{\circ} \mathrm{C} / \mathrm{min}$ under nitrogen atmosphere. Differential scanning calorimetry (DSC 4000, Netzsch, Germany) was used to record the heat storage/releasing capacities of MPCMs and treated fabrics. Measurements were done by varying the temperature in the range from $0{ }^{\circ} \mathrm{C}$ to $70{ }^{\circ} \mathrm{C}$ with a heating rate of $10{ }^{\circ} \mathrm{C} / \mathrm{min}$.

The encapsulation efficiency $\left(E_{e n}\right)$ of MPCMs was calculated from the DSC results by the following equation (1)(Gao et al. 2017) 
$E_{e n}=\frac{\Delta H_{m, C o r e}}{\Delta H_{m, P C M}} \times 100 \%$

where $\Delta \mathrm{H}_{\mathrm{m} \text {,core }}$ and $\Delta \mathrm{H}_{\mathrm{m}, \mathrm{PCM}}$ are the melting enthalpies of pure n-octadecane and the MPCM, respectively.

The thermo-regulating performance of pristine and treated fabrics was recorded by an infrared thermal camera (Fluke TiX450, USA). The samples were set in a heating plate $\left(40{ }^{\circ} \mathrm{C}\right)$ and the infrared thermal camera was used to capture changes in temperature of the samples. To test washfastness of the treated fabrics, the samples were soaked in a solution of standard soap $(2.0 \mathrm{~g} / \mathrm{L})$ at a liquor ratio of 1:50, and washed for $30 \mathrm{~min}$ at $45^{\circ} \mathrm{C}$ in a SBW-12 laundry machine. This operation was repeated for 30 times and the sample was coded as Wash-30.

\section{Results And Discussion}

\section{Characterization of MPCMs}

Due to the superior emulsifying ability of RCh, Pickering emulsions stabilized by as little as $0.10 \mathrm{wt} \% \mathrm{RCh}$ have been be successfully. Fig. 2a shows the optical microscopic image of such a Pickering emulsion of n-octadecane in water stabilized by 0.15 wt \% RCh, which shows droplets sized between 10-30 $\mu \mathrm{m}$.

Morphology of the corresponding MPCMs generated from the emulsion is shown in Fig. $2 \mathrm{~b}$ and Fig. 2c. It can be seen from the images that the microcapsules are well separated and no agglomeration is noticed. The diameter of the spherical MPCMs corresponds well with that of the droplets, ranging from $10 \mu \mathrm{m}$ to $30 \mu \mathrm{m}$. The surfaces of the microcapsules appear to be wrinkled with protrusions and indentations likely caused by the voluminal shrinkage of n-octadecane during liquid to solid transition(Qiu et al. 2018).

Thermal stability of octadecanethe MPCMs was evaluated and compared to that of pure n-octadecane by TG (Fig. 2d and Table S2). Results show that pure n-octadecane exhibited a typical one-step weight loss curve spanning from $133^{\circ} \mathrm{C}$ to $230^{\circ} \mathrm{C}$, with a $\mathrm{T}_{\max }$ (temperature at which the maximum weight loss rate occurs) at $230.9^{\circ} \mathrm{C}$ due to evaporation and left almost no residue (Li et al. 2019a; Xu and Yang 2019). An obvious thermal stability enhancement was achieved for the MPCM as indicated by the increment in $\mathrm{T}_{\max }$ by about $45^{\circ} \mathrm{C}$ compared with pure n-octadecane. The three distinct stages observed in the decomposition curve of MPCMs can be attributed to gasification of n-octadecane and decomposition of the PU shell(Ma et al. 2015b), respectively. The final char residue was also low at $0.09 \%$.

Melting enthalpy $\left(\Delta \mathrm{H}_{\mathrm{m}}\right)$ and crystallization enthalpy $\left(\Delta \mathrm{H}_{\mathrm{c}}\right)$ are two important indexes representing the thermal storage/release capability of MPCMs. Fig. 2(e) displayed the DSC curves of MPCMs as compared with that of pure n-octadecane. Form Fig. 2(e), the melting and crystallization temperature of MPCM were slightly lower than that of pure n-octadecane. It is because that motion of the n-octadecane molecules was limited by the confined internal spaces of microcapsules, resulting in the crystallization 
defects $\left(\mathrm{Li}\right.$ et al. 2020). Based on the $\Delta \mathrm{H}_{\mathrm{m}}$ of pure n-octadecane $(246.0 \mathrm{~J} / \mathrm{g})$ and MPCMs $(190.8 \mathrm{~J} / \mathrm{g})$, the encapsulation rate of the microcapsules was calculated to be $77.3 \%$ according to equation (1).

Characterization of the treated cotton fabrics

Chemical compositions of the microcapsules and treated fabrics

The changes in chemical composition during the preparation process were studied by FT-IR. As shown in Fig. 3(a), the IR spectrum of MPCMs shows a peak at $2260 \mathrm{~cm}^{-1}$, characteristic of -NCO stretching(Shi et al. 2019). MPCMs also show a broad peak at about $3330 \mathrm{~cm}^{-1}$ corresponding to stretching vibrations of $\mathrm{NHs}$ and $-\mathrm{OHs}$. The existence of the stretching vibrations of $-\mathrm{NH}$ and $-\mathrm{C}=\mathrm{O}$ at $1560 \mathrm{~cm}^{-1}$ and $1637 \mathrm{~cm}^{-1}$ illustrated that the PU shell was successfully formed by the isocyanate-amidogen reaction(Qian et al. 2020; Wu et al. 2015). These peaks also appear in the spectrum of treated cotton fabrics, which also show additional peaks at $1069 \mathrm{~cm}^{-1}$ and $1240 \mathrm{~cm}^{-1}$, due to the presence of $\mathrm{P}-\mathrm{O}$ and $\mathrm{P}=0$ moieties(Peng et al. 2020; Ullah et al.) compared with pristine cotton. These results suggest that the LBL treatment yielded a physical composite of MPCM, APP and cotton.

\section{Surface Morphology}

The morphology of pristine and treated fabrics were examined by SEM (Fig. 4). As shown by the SEM images, the pristine cotton fabric displayed a typical morphology of woven fabrics with smooth fiber surface. After 5 cycles of repeated LBL treatment (MPCM/APP-5), the cellulose fibers were clearly covered by discrete films but remained distinguishable. Surface of MPCM/APP-10 was clearly covered by continuous thin films and MPCMs. When the number of bilayers increased to 15 (MPCM/APP-15) and 20 (MPCM/APP-20), the cellulose fibers became completely undistinguishable. Moreover, the thickness of the samples increased from $0.25 \mathrm{~mm}$ (pristine cotton) to $0.26 \mathrm{~mm}, 0.27 \mathrm{~mm}, 0.28 \mathrm{~mm}$ and $0.29 \mathrm{~mm}$, respectively with $5,10,15$, and 20 cycles of LBL treatment (Fig. S2) These results confirmed that APP and MPCMs were successfully deposited on the surface of the cotton fabrics.

Thermal stability

Fig. 5a shows the TG curves of the pristine and treated cotton fabrics heated up to $700{ }^{\circ} \mathrm{C}$. The corresponding thermal degradation data are listed in Table 1. The pristine cotton exhibited a one-step weight loss curve due to the depolymerization of glycosyl units and left about $6.78 \%$ residue. In contrast, all treated fabrics displayed a two-staged weight loss pattern. The first weight loss occurred at around $150{ }^{\circ} \mathrm{C}$, which was significantly lower than the $\mathrm{T}_{\text {onset }}$ of pristine cotton $\left(261.2^{\circ} \mathrm{C}\right)$ and could be attributed to evaporation of n-octadecane as observed in the TG curve of the MPCMs. The resulting polyphosphoric 
acid promoted carbonize of cotton cellulose to formation of an intumescent char layer(Xue et al. 2020) that prevent further decomposition of cellulose and MPCMs(Fang et al. 2015; Horrocks 2011). As a result, although $T_{\max 2}$ values of MPCM/APP-5, MPCM/APP-10, MPCM/APP-15 and MPCM/APP-20 were all lower than that of the pristine cotton, their yields of charwere significantly higher. It is well known that flame retardancy of materials is reflected by their yield of char in pyrolysis(Wang et al. 2015). Therefore, the APP treatment was effective in enhancing the flame retardancy of the cotton fabrics by promoting charring to suppress thermal oxidation degradation(Shi et al. 2018).

Thermal storage capacity and thermo-regulating performance

The MPCMs possess high phase change enthalpy measured to be $190.8 \mathrm{~J} / \mathrm{g}$, which is expected to endow the cotton fabrics with active thermo-regulating function. The heat storage capacities of treated fabrics were measured by DSC and the corresponding curves and melting and crystallization parameters are shown in Fig. 4c and Table 2. As expected, the latent heat of treated fabrics gradually increased from $13.01 \mathrm{~J} / \mathrm{g}$ to $30.16 \mathrm{~J} / \mathrm{g}$ with increasing number of deposited layers from 5 to 20 . The melting and crystallization temperature of all treated fabrics are about $30{ }^{\circ} \mathrm{C}$ and $22{ }^{\circ} \mathrm{C}$, respectively, showing distinct difference than the MPCMs. Thus, it can be considered that the Layer-by-Layer coating process had little effect on the melting and crystallization performance of the microcapsules.

Garments made from MPCM-containing textiles can provide superior protection to the wearer in extreme environmental conditions, for they are endowed, by the MPCMs, the ability to store and release energy in a certain temperature range. Herein, temperature-regulating performance of MPCM/APP-20 was evaluated and compared to that of pristine cotton and using a hot plate set at about $40{ }^{\circ} \mathrm{C}$. An infrared thermal camera was used to capture changes in temperature of these samples. As seen in Fig. $5 \mathrm{c}$, there was a significant temperature difference between MPCM/APP-20 and pristine cotton during the heating process. Pristine cotton was quickly heated to $40.9^{\circ} \mathrm{C}$ within $10 \mathrm{~s}$, by which time the surface of MPCM/APP-20 was measured to be $34.5^{\circ} \mathrm{C}, 6.4^{\circ} \mathrm{C}$ lower than the set temperature of the hot plate. By 40 $\mathrm{s}$, the surface temperature of MPCM/APP-20 was still $3.8^{\circ} \mathrm{C}$ lower than the set value. These results confirmed that efficient thermo-regulating ability could be imparted to cotton fabrics by this LBL strategy.

Table 1 Thermal degradation data of MPCM, treated fabrics and after being washed 


\begin{tabular}{|lllll|}
\hline Sample & $\mathrm{T}_{\text {onest }}\left({ }^{\circ} \mathrm{C}\right)$ & $\mathrm{T}_{\max 1}\left({ }^{\circ} \mathrm{C}\right)$ & $\mathrm{T}_{\max 2}\left({ }^{\circ} \mathrm{C}\right)$ & Char residues at $700^{\circ} \mathrm{C}(\mathrm{wt} \%)$ \\
\hline Cotton & 261.2 & 369.2 & - & 6.78 \\
\hline MPCM/APP-5 & 118.2 & 148.5 & 318.9 & 26.31 \\
\hline MPCM/APP-10 & 116.6 & 168.3 & 312.9 & 30.25 \\
\hline MPCM/APP-15 & 118.2 & 166.9 & 309.9 & 32.49 \\
\hline MPCM/APP-20 & 115.0 & 166.9 & 308.3 & 34.24 \\
\hline Wash-30 & 119.6 & 168.3 & 325.1 & 19.82 \\
\hline
\end{tabular}

Table 2 The corresponding DSC data of n-octadecane, MPCM, treated fabrics and after being washed

\begin{tabular}{|lllll|}
\hline Sample & \multicolumn{3}{l}{ Melting } & \multicolumn{2}{l|}{ Crystalling } \\
\cline { 2 - 5 } & $\mathrm{T}_{\mathrm{m}}$ & $\Delta \mathrm{H}_{\mathrm{m}}(\mathrm{J} / \mathrm{g})$ & $\mathrm{T}_{\mathrm{c}}$ & $\Delta \mathrm{H}_{\mathrm{c}}(\mathrm{J} / \mathrm{g})$ \\
\hline n-octadecane & 34.13 & 246.6 & 19.11 & 245.1 \\
\hline MPCM & 34.04 & 190.8 & 25.19 & 190.4 \\
\hline MCPM/APP-5 & 30.10 & 13.01 & 22.53 & 11.65 \\
\hline MCPM/APP-10 & 31.20 & 20.59 & 22.16 & 19.33 \\
\hline MCPM/APP-15 & 30.37 & 24.46 & 22.31 & 23.52 \\
\hline MCPM/APP-20 & 31.54 & 30.16 & 21.67 & 29.15 \\
\hline Wash-30 & 27.64 & 17.14 & 19.42 & 15.64 \\
\hline
\end{tabular}

Flame retardancy of the treated fabric

LOI is used to evaluate the fire resistance of treated fabrics and the results are shown in Fig. 6. LOI of the cotton fabrics increased from $17.9 \%$ to over $24 \%$ after 15 cycles of LBL treatments, suggesting the incorporated APP was effective in improving the flame retardancy of the fabrics. However, further increase of the deposited layers from 15 to 20 didn't lead to appreciable improvement in LOI. Considering the handle and wearability of the fabrics are negatively affected by the number of deposited layers, MPCM/APP-15 seems to be the optimum choice.

The treated fabrics were burned and their surface morphology analyzed by SEM (Fig. 7). Surprisingly, not only the fibers in the burnt fabrics remained distinguishable, some of the MPCMs were also intact, indicating the presence of APP also protected the microcapsules from being destroyed by burning. 


\section{Durablility test}

Washfastness of MPCM/APP-20 was evaluated using by repeatedly wash the sample using a SBW-12 laundry machine. Fig. 8a shows the SEM image of MPCM/APP-20 after being washed for 30 times. The film and MPCMs covering the surface of fabric were still present, while some of the underlying fibers were also revealed, indicating that MPCM and APP were partially lost after repeated laundering. Results from the TG analysis (Fig. 8b) showed the TG curve of the washed sample was very similar to the unwashed one, but with markedly reduced amount of residue char (decreased by $42 \%$ ). The results indicated that although washing had no significant impact on the thermal stability of the treated fabric, the flameretardancy were moderately impaired.

The DSC curves and data of MPCM/APP-20 after being washed is presented in Fig $6 \mathrm{c}$. The melting and crystallization enthalpies of the washed samples were calculated to be $24.89 \mathrm{~J} / \mathrm{g}$ and $25.39 \mathrm{~J} / \mathrm{g}$, respectively, representing a $43.1 \%$ drop compared with pre-wash values. These results collectively showed that both the thermo-regulating property and flame retardancy imparted to the cotton fabric by the LbL technology were moderately durable against repeated washing.

\section{Conclusions}

In this paper, Layer-by-Layer assembly technology was used to coat cotton fabric with a thermoregulating and flame retardant fishing. The morphology and the distribution of elements of treated fabrics were examined by SEM and EDX, illustrating MPCMs and APP were successfully deposited on the fabrics. The fabric with 20 deposited multilayers, MPCM/APP-20, displayed a latent heat of $30.16 \mathrm{~J} / \mathrm{g}$ and reasonable thermo-regulating performance. It also showed enhanced flame retardancy with LOI of $24.4 \%$ and residual char of $34.24 \%$. After being washed 30 times, MPCM/APP-20 was able to maintain $57.9 \%$ of its original enthalpy and still showed moderated flame retardancy, demonstrating the LbL technology as a facile and eco-friendly strategy for imparting durable thermo-regulating ability and flame retardancy to cotton fabrics.

\section{Declarations}

\section{Acknowledgements}

This work was financially supported by Fundamental Research Funds for the Central Universities (No. 2232020G-04)

\section{References}

Alay Aksoy S, Alkan C, Tözüm MS, Demirbağ S, Altun Anayurt R, Ulcay Y (2017) Preparation and textile application of poly (methyl methacrylate-co-methacrylic acid)/n-octadecane and n-eicosane 
microcapsules. J. Tex. Inst 108:30-41. https://doi.org/10.1080/00405000.2015. 1133128

Ali A, Baheti V, Vik M, Militky J (2020) Copper electroless plating of cotton fabrics after surface activation with deposition of silver and copper nanoparticles. J. Phys.Chem. Solids 137:109181. https://doi.org/10.1016/j.jpcs.2019.109181

Bashari A, Koohestani AHS, Salamatipour N (2020) Eco-friendly dual-tunctional textiles: green waterrepellent \& anti-bacterial. Fiber. Polym 21:317-323. https://doi.org/10.1007/s12221-020-9568-6

Benmoussa D, Molnar K, Hannache H, Cherkaoui O (2018) Novel thermo-regulating comfort textile based on poly(allyl ethylene diamine)/n-hexadecane microcapsules grafted onto cotton Fabric. Adv. Polym. Tech 37:419-428. https://doi.org/10.1002/adv.21682

Bonet MÁ, Capablanca L, Monllor P, Díaz P, Montava I (2012) Studying bath exhaustion as a method to apply microcapsules on fabrics. J. Tex. Inst 103:629-635. https://doi.org/10.1080/ 00405000.2011 .596665

Carosio F, Negrell-Guirao C, Di Blasio A, Alongi J, David G, Camino G (2015) Tunable thermal and flame response of phosphonated oligoallylamines layer by layer assemblies on cotton. Carbohydr. Polym 115:752-759. https://doi.org/10.1016/j.carbpol.2014.06.066

Demirbağ S, Aksoy SA (2016) Encapsulation of phase change materials by complex coacervation to improve thermal performances and flame retardant properties of the cotton fabrics. Fiber. Polym 17:408417. https://doi.org/10.1007/s12221-016-5113-z

Fang F et al. (2015) Intumescent flame retardant coatings on cotton fabric of chitosan and ammonium polyphosphate via layer-by-layer assembly. Surf. Coat. Technol 262:9-14.

https://doi.org/10.1016/j.surfcoat.2014.11.011

Fang Y, Liu X, Tao X (2019) Intumescent flame retardant and anti-dripping of PET fabrics through layerby-layer assembly of chitosan and ammonium polyphosphate. Prog. Org. Coat 134:162-168. https://doi.org/10.1016/j.porgcoat.2019.05.010

Gao F, Wang X, Wu D (2017) Design and fabrication of bifunctional microcapsules for solar thermal energy storage and solar photocatalysis by encapsulating paraffin phase change material into cuprous oxide. Sol. Energy Mater. Sol. Cells 168:146-164. https://doi.org/10.1016/ j.solmat.2017.04.026

Horrocks AR (2011) Flame retardant challenges for textiles and fibres: New chemistry versus innovatory solutions. Polym. Degrad. Stabil 96:377-392. https://doi.org/10.1016/j.polymdegradstab. 2010.03.036

lqbal K, Sun D (2014) Development of thermo-regulating polypropylene fibre containing microencapsulated phase change materials. Renew. Energy 71:473-479. https://doi.org/ 10.1016/j.renene.2014.05.063 
Iqbal K, Sun D (2018) Synthesis of nanoencapsulated Glauber's salt using PMMA shell and its application on cotton for thermoregulating effect. Cellulose 25:2103-2113. https://doi.org/ $10.1007 / \mathrm{s} 10570-018-1692-8$

Jin X, Medina MA, Zhang X (2013) On the importance of the location of PCMs in building walls for enhanced thermal performance. Appl. Energy 106:72-78. https://doi.org/10.1016/j.apenergy. 2012.12.079

Kumar A, Kulkarni PS, Samui A (2014) Polyethylene glycol grafted cotton as phase change polymer Cellulose 21:685-696. https://doi.org/10.1007/s10570-013-0120-3

Li C, Yu H, Song Y, Liang H, Yan X (2019a) Preparation and characterization of PMMA/TiO 2 hybrid shell microencapsulated PCMs for thermal energy storage. Energy 167:1031-1039. https:// doi.org/10.1016/j.energy.2018.11.038

Li J, Wang B, Ye G, Xu J, Jiang M (2013) Study of synthesizing energy storage microcapsules in PVA spinning solution and thermal regulating fibers prepared by this solution. Fiber. Polym 14:537-541. https://doi.org/10.1007/s12221-013-0537-1

Li S, Lin X, Li Z, Ren X (2019b) Hybrid organic-inorganic hydrophobic and intumescent flame-retardant coating for cotton fabrics. Compos. Commun 14:15-20. https://doi.org/10.1016/j.coco. 2019.05.005

Li W, Ma YJ, Tang XF, Jiang N, Zhang R, Han N, Zhang XX (2014) Composition and characterization of thermoregulated fiber containing acrylic-based copolymer microencapsulated phase-change materials (MicroPCMs). Ind. Eng. Chem. Res 53:5413-5420. https://doi.org/10.1021/ie404174a

Li X, Wang Y, Wang B, Feng X, Mao Z, Sui X (2020) Antibacterial phase change microcapsules obtained with lignin as the Pickering stabilizer and the reducing agent for silver. Int. J. Bio. Macromol 144:624-631. https://doi.org/10.1016/j.ijbiomac.2019.12.016

Liu J, Wang Q, Fan XR (2012) Layer-by-layer self-assembly of $\mathrm{TiO}_{2}$ sol on wool to improve its antiultraviolet and anti-ageing properties. J. Sol-Gel Sci. Technol 62:338-343. https://doi.org/ $10.1007 /$ s10971-012-2730-x

Liu Z, Zang C, Ju Z, Hu D, Zhang Y, Jiang J, Liu C (2020) Consistent preparation, chemical stability and thermal properties of a shape-stabilized porous carbon/paraffin phase change materials. J. Clean. Prod 247:119565. https://doi.org/10.1016/j.jclepro.2019.119565

Ma $\mathrm{Y}$ et al. (2015a) Synthesis and characterization of thermal energy storage microencapsulated $\mathrm{n}$ dodecanol with acrylic polymer shell. Energy 87:86-94. https://doi.org/10.1016/j.energy. 2015.04.096

Ma YJ et al. (2015b) Synthesis and characterization of thermal energy storage microencapsulated ndodecanol with acrylic polymer shell. Energy 87:86-94. https://doi.org/10.1016/j.energy. 2015.04.096 
Masood R, Jamshaid H, Khubaib MA (2020) Development of knitted vest fabrics for human body thermoregulation. J. Therm. Anal. Calorim 139:159-167. https://doi.org/10.1007/s10973-019-08430-2

Mohaddes F, Islam S, Shanks R, Fergusson M, Wang L, Padhye R (2014) Modification and evaluation of thermal properties of melamine-formaldehyde/n-eicosane microcapsules for thermo-regulation applications. Appl. Therm. Eng 71:11-15. https://doi.org/10.1016/j.applthermaleng. 2014.06.016

Peng S, Wang Y, Lan Y, Shi X, Zhang H, Qu H, Xu J (2020) Rational design of multifunctional superoleophobic/superhydrophilic, photocatalytic, and fire-retardant polyethylene terephthalate fabrics through layer-by-layer technique. Compos. B. Eng 200:108264. https://doi.org/10.1016/ j.compositesb.2020.108264

Prajapati DG, Kandasubramanian B (2019) A review on polymeric-based phase change material for thermo-regulating fabric application. Polym. Rev 60: 389-419. https://doi.org/10.1080/ 15583724.2019.1677709

Qian Y, Zhou YJ, Li L, Liu WF, Yang DJ, Qiu XQ (2020) Facile preparation of active lignin capsules for developing self-healing and UV-blocking polyurea coatings. Prog. Org. Coat 138:105354. https://doi.org/10.1016/j.porgcoat.2019.105354

Qiao X, Kong X, Li H, Wang L, Long H (2020) Performance and optimization of a novel active solar heating wall coupled with phase change material. J. Clean. Prod 250:119470. https://doi.org/ 10.1016/j.jclepro.2019.119470

Qiu X, Lu L, Chen Z (2015) Preparation and characterization of flame retardant phase change materials by microencapsulated paraffin and diethyl ethylphosphonate with poly(methacrylic acid-co-ethyl methacrylate) shell. J. Appl. Polym. Sci 132:41880. https://doi.org/10.1002/app.41880

Qiu XZ, Tao Y, Xu XQ, He XH, Fu XY (2018) Synthesis and characterization of paraffin/TiO 2 -P(MMA-coBA) phase change material microcapsules for thermal energy storage. J. Appl. Polym. Sci 135:46447. https://doi.org/10.1002/app.46447

Sánchez P, Sánchez-Fernandez MV, Romero A, Rodríguez JF, Sánchez-Silva L (2010) Development of thermo-regulating textiles using paraffin wax microcapsules. Thermochim. Acta 498:16-21. https://doi.org/ 10.1016/j.tca.2009.09.005

Saini S, Gupta A, Singh N, Sheikh J (2020) Functionalization of linen fabric using layer by layer treatment with chitosan and green tea extract. J. Ind. Eng. Chem 82:138-143. https://doi.org/ 10.1016/j.jiec.2019.10.005

Saraç EG, Öner E, Kahraman MV (2019) Microencapsulated organic coconut oil as a natural phase change material for thermo-regulating cellulosic fabrics. Cellulose 26:8939-8950. https://doi.org/10.1007/s10570-019-02701-9 
Scacchetti FAP, Pinto E, Soares GMB (2017) Functionalization and characterization of cotton with phase change materials and thyme oil encapsulated in beta-cyclodextrins. Prog. Org. Coat 107:64-74. https://doi.org/10.1016/j.porgcoat.2017.03.015

Shi XH, Xu YJ, Long JW, Zhao Q, Ding XM, Chen L, Wang YZ (2018) Layer-by-layer assembled flameretardant architecture toward high-performance carbon fiber composite. Chem. Eng. J 353:550-558. https://doi.org/10.1016/j.cej.2018.07.146

Shi XY, Liu CL, Li KX, Shi ZS, Cui ZC (2019) Effect of microcapsules partially filled with viscoelastic acrylate polymer on damping behaviours of epoxy resin. New J. Chem 43:9824-9831. https://doi.org/10.1039/c9nj01143a

Su JF, WangXY Han S, Zhang XL, Guo YD, Wang YY, Tan YQ, Han NX, Li W (2017) Preparation and physicochemical properties of microcapsules containing phase-change material with graphene/organic hybrid structure shells. J. Mater. Chem. A 5:23937-23951. https://doi.org/ 10.1039/c7ta06980d

Su Y, Zhu W, Tian M, Wang YY, Zhang XH, Li J (2020) Intelligent bidirectional thermal regulation of phase change material incorporated in thermal protective clothing. Appl. Therm. Eng 174:115340. https://doi.org/10.1016/j.applthermaleng.2020.115340

Sun D, lqbal K (2017) Synthesis of functional nanocapsules and their application to cotton fabric for thermal management. Cellulose 24:3525-3543. https://doi.org/10.1007/s10570-017-1326-6

Ullah S, Ahmad F, Al-Sehemi AG, Assiri MA, Raza MR, Irfan A (2020) Effect of expandable graphite and ammonium polyphosphate on the thermal degradation and weathering of intumescent fire-retardant coating. J. Appl. Polym. Sci 27:50310. https://doi.org/10.1002/app.50310

Vitorino N, Abrantes JCC, Frade JR (2014) Highly conducting core-shell phase change materials for thermal regulation. Appl. Therm. Eng 66:131-139. https://doi.org/10.1016/j.applthermaleng. 2014.02.001

Wang T, Wang S, Luo R, Zhu C, Akiyama T, Zhang Z (2016) Microencapsulation of phase change materials with binary cores and calcium carbonate shell for thermal energy storage. Appl. Energy 171:113-119. https://doi.org/10.1016/j.apenergy.2016.03.037

Wang X, Quintero Romero M, Zhang XQ, Wang R, Wang DY (2015) Intumescent multilayer hybrid coating for flame retardant cotton fabrics based on layer-by-layer assembly and sol-gel process. Rsc Adv 5:10647-10655. https://doi.org/10.1039/c4ra14943b

Wu Q, Zhao D, Jiao X, Zhang Y, Shea KJ, Lu XH, Qiu G (2015) Preparation, properties, and supercooling prevention of phase change material n-octadecane microcapsules with peppermint fragrance scent. Ind. Eng. Chem. Res 54:8130-8136. https://doi.org/10.1021/acs.iecr.5b01074

Xu D, Yang R (2019) Efficient preparation and characterization of paraffin-based microcapsules by emulsion polymerization. J. Appl. Polym. Sci 136:47552. https://doi.org/10.1002/app.47552 
Xue CH, Wu Y, Guo XJ, Liu BY, Wang HD, Jia ST (2020) Superhydrophobic, flame-retardant and conductive cotton fabrics via layer-by-layer assembly of carbon nanotubes for flexible sensing electronics. Cellulose 27:3455-3468. https://doi.org/10.1007/s10570-020-03013-z

Zhao CY, Zhang GH (2011) Review on microencapsulated phase change materials (MEPCMs): Fabrication, characterization and applications. Renew. Sust. Energ. Rev 15:3813-3832. https:// doi.org/10.1016/j.rser.2011.07.019

Zhu X et al. (2020) Stable microencapsulated phase change materials with ultrahigh payload for efficient cooling of mobile electronic devices. Energy Conv. Manag 223: 113478. https://doi.org/ 10.1016/j.enconman.2020.113478

\section{Figures}

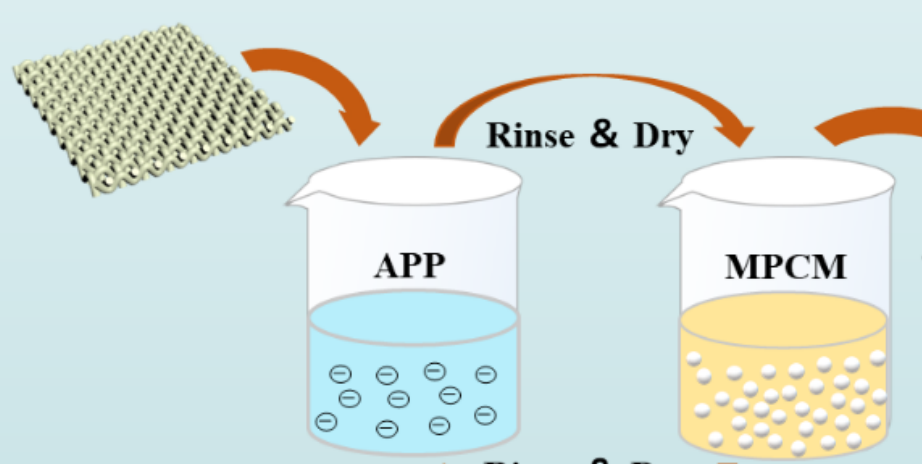

\section{Rinse \& Dry}

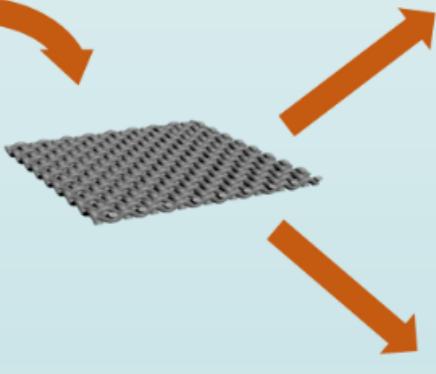

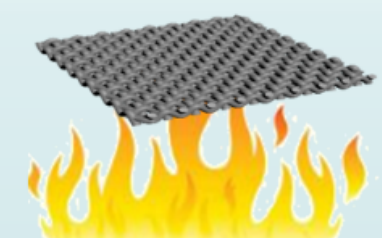

Flame Retardant

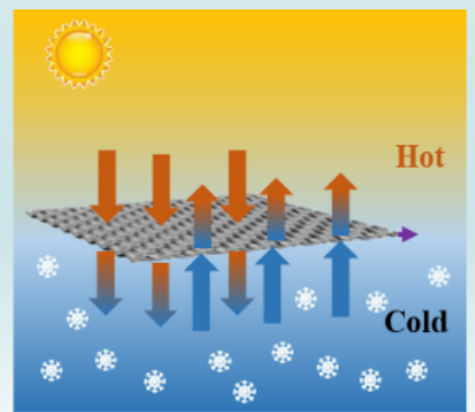

Temperature Regulation

\section{Figure 1}

Schematic illustration of thermo-regulating and flame retardant cotton fabric using layer-by-layer assembly 

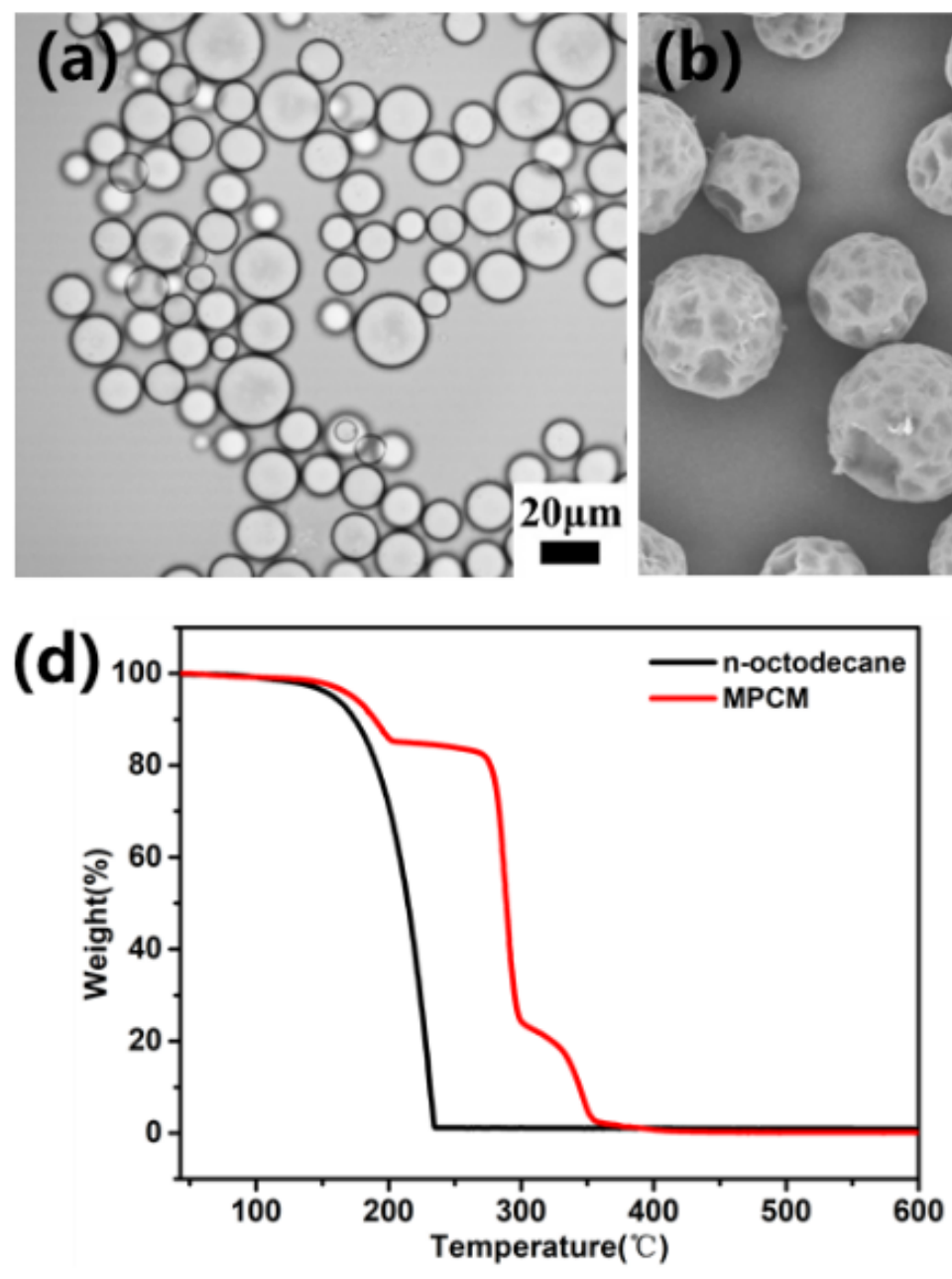
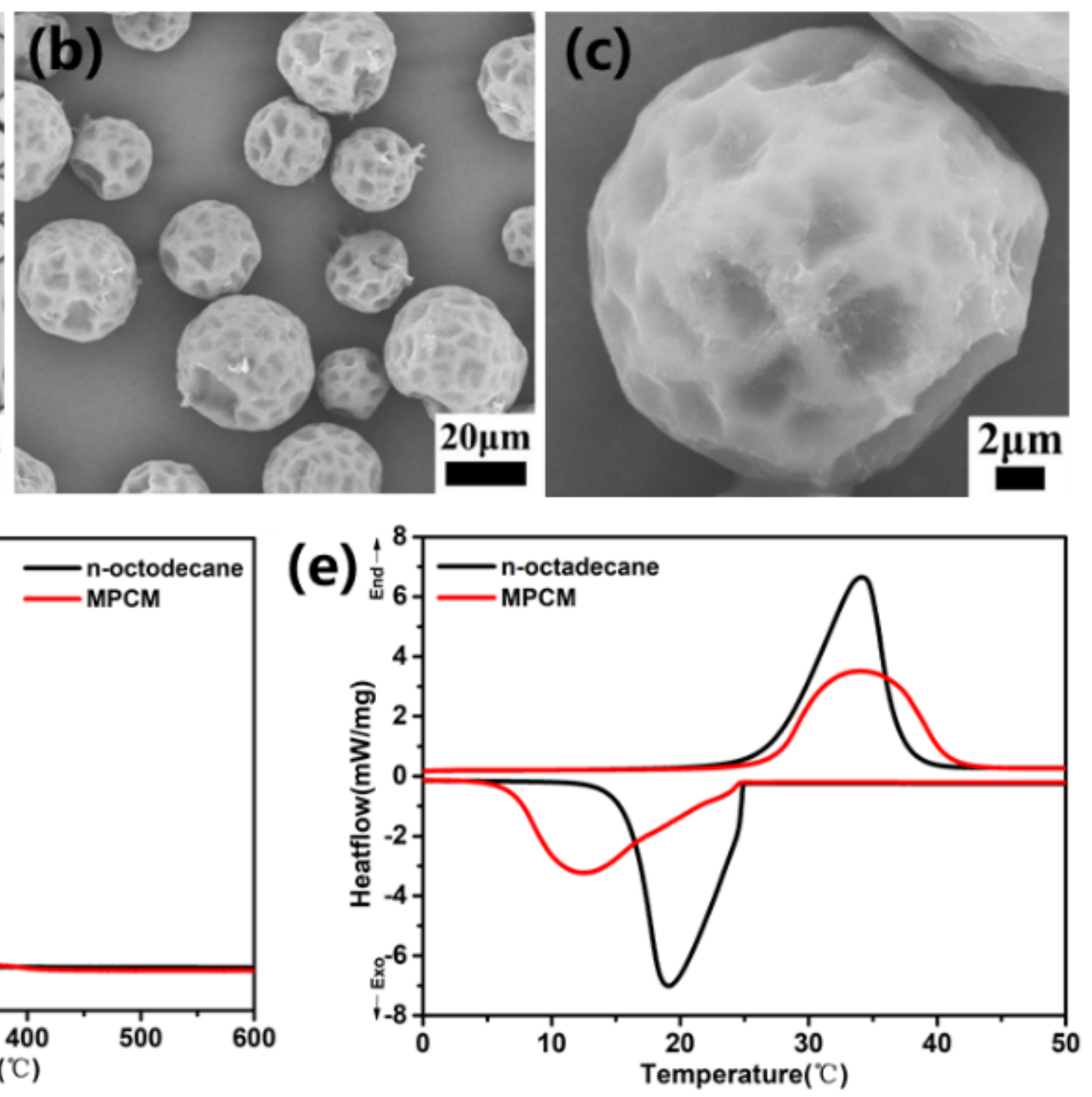

Figure 2

(a) Optical microscopic image of O/W Pickering emulsion stabilized by RCh suspension; (b, c) SEM images of MPCMs at different distinguishability; (d) TG curves of n-octadecane and MPCM; and (e) DSC curves of n-octadecane and MPCM 


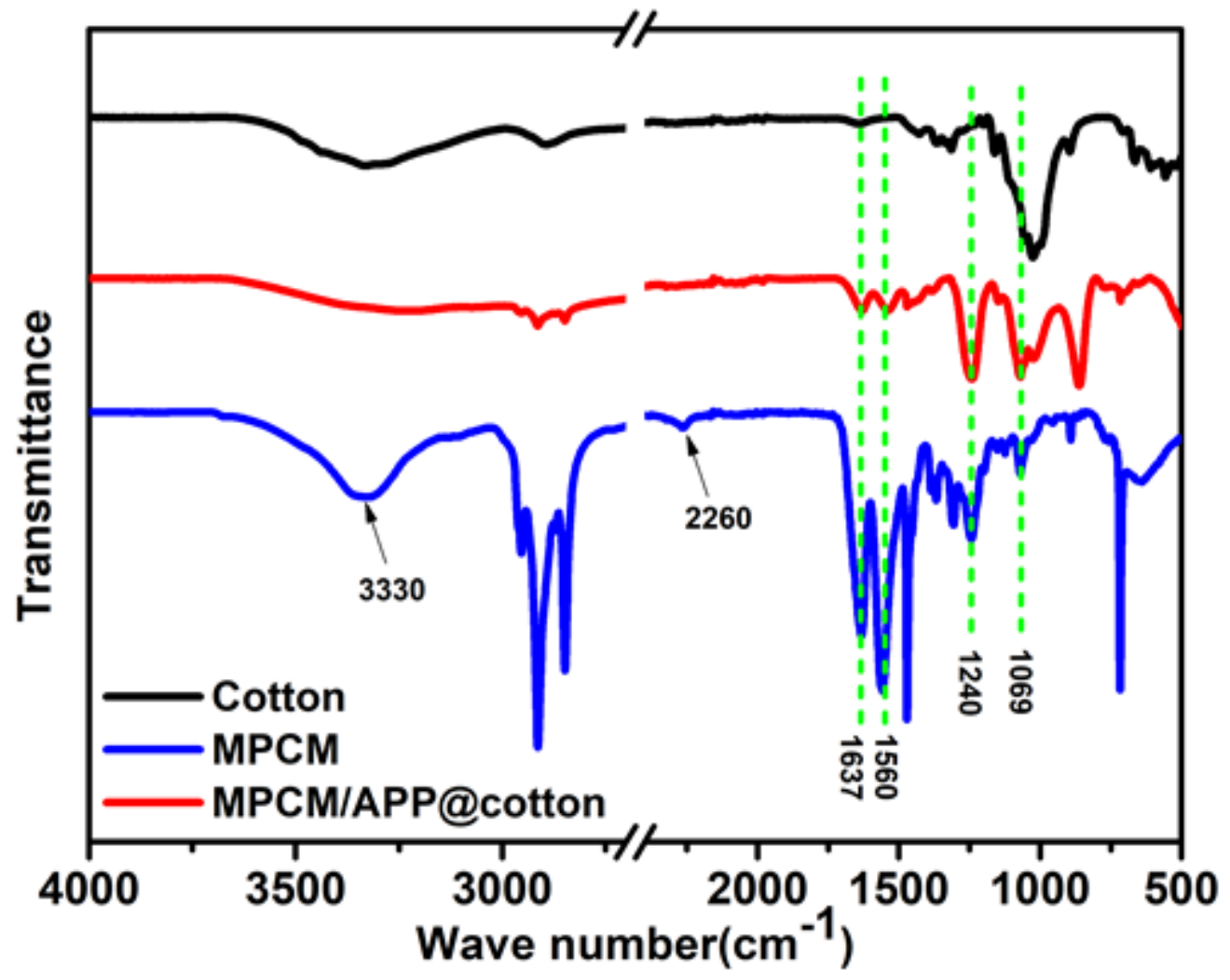

Figure 3

FT-IR spectra of pristine cotton, MPCMs and the treated fabric (MPCM/APP@cotton)
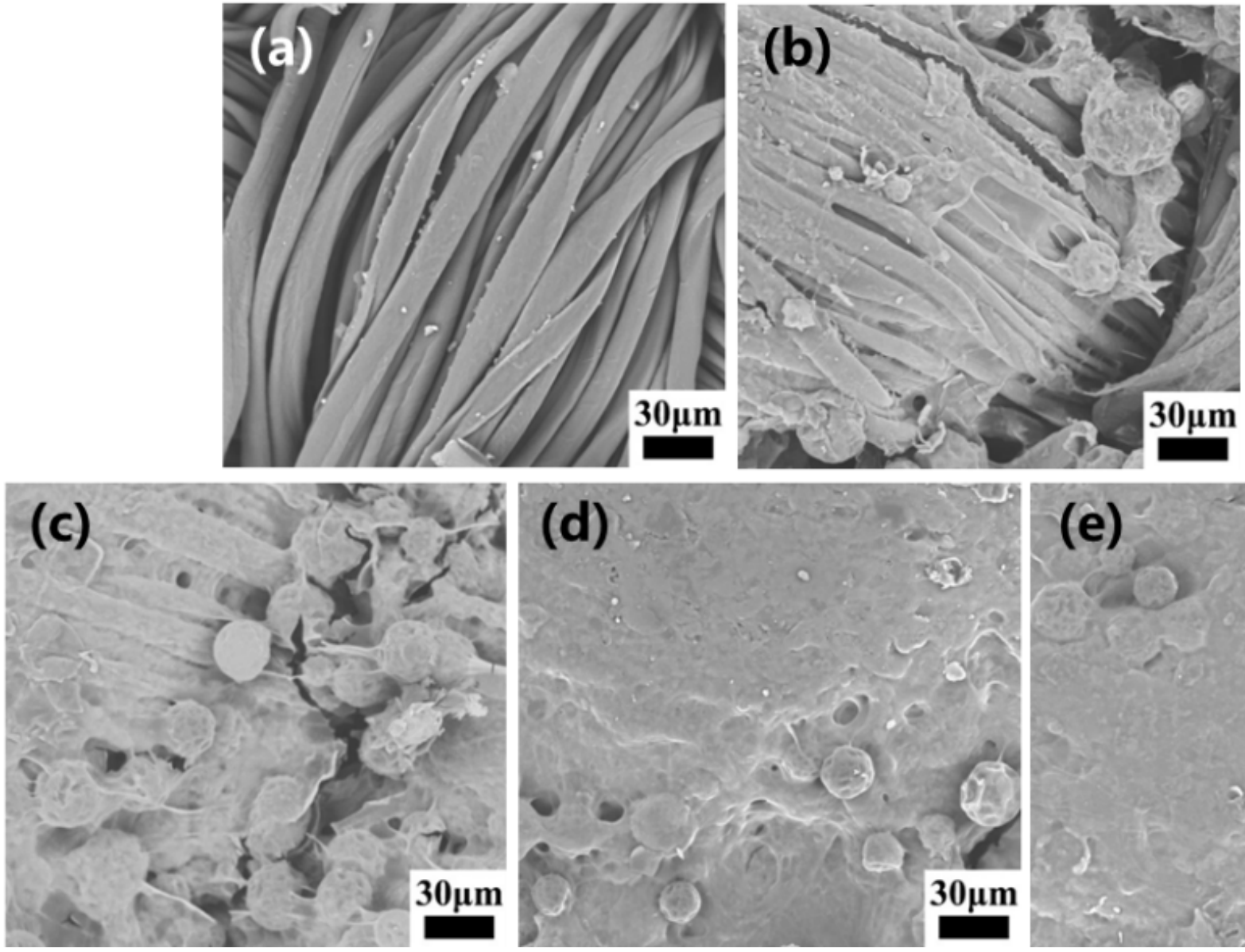

(e) 
Figure 4

Surface morphology of pristine cotton and treated cotton fabrics. (a) SEM of pristine cotton; (b) SEM of MPCM/APP-5; (c) MPCM/APP-10; (d) MPCM/APP-15; (e) MPCM/APP-20
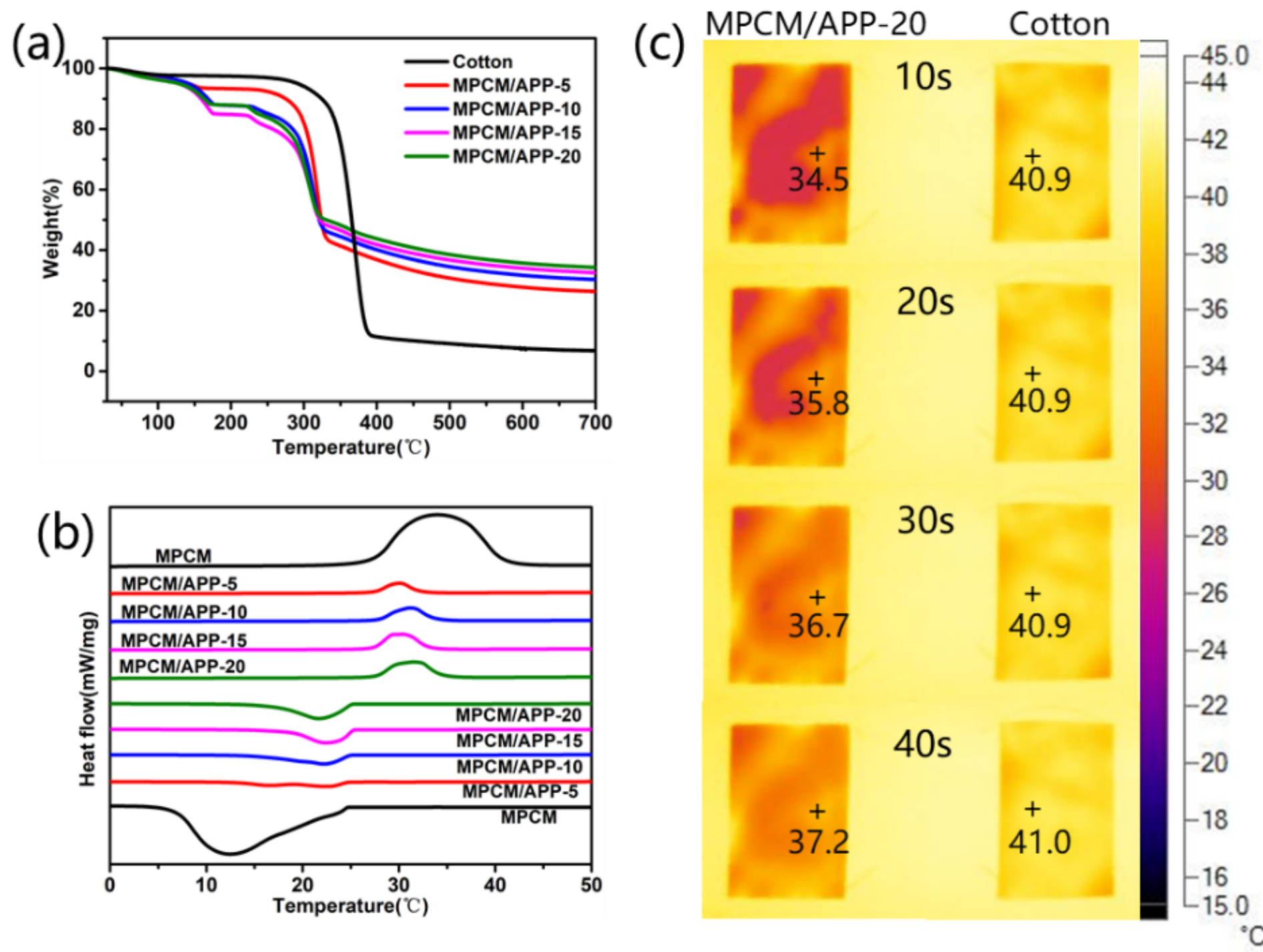

\section{Figure 5}

(a) Thermal stability and thermal storage capacity of cotton and treated cotton. TG curves of cotton and treated cotton; (b) DSC curves of MPCM and treated cotton; (c) Infrared thermal imaging monitored the heating process of the fabric at a heating plate $\left(\approx 40^{\circ} \mathrm{C}\right)$ 


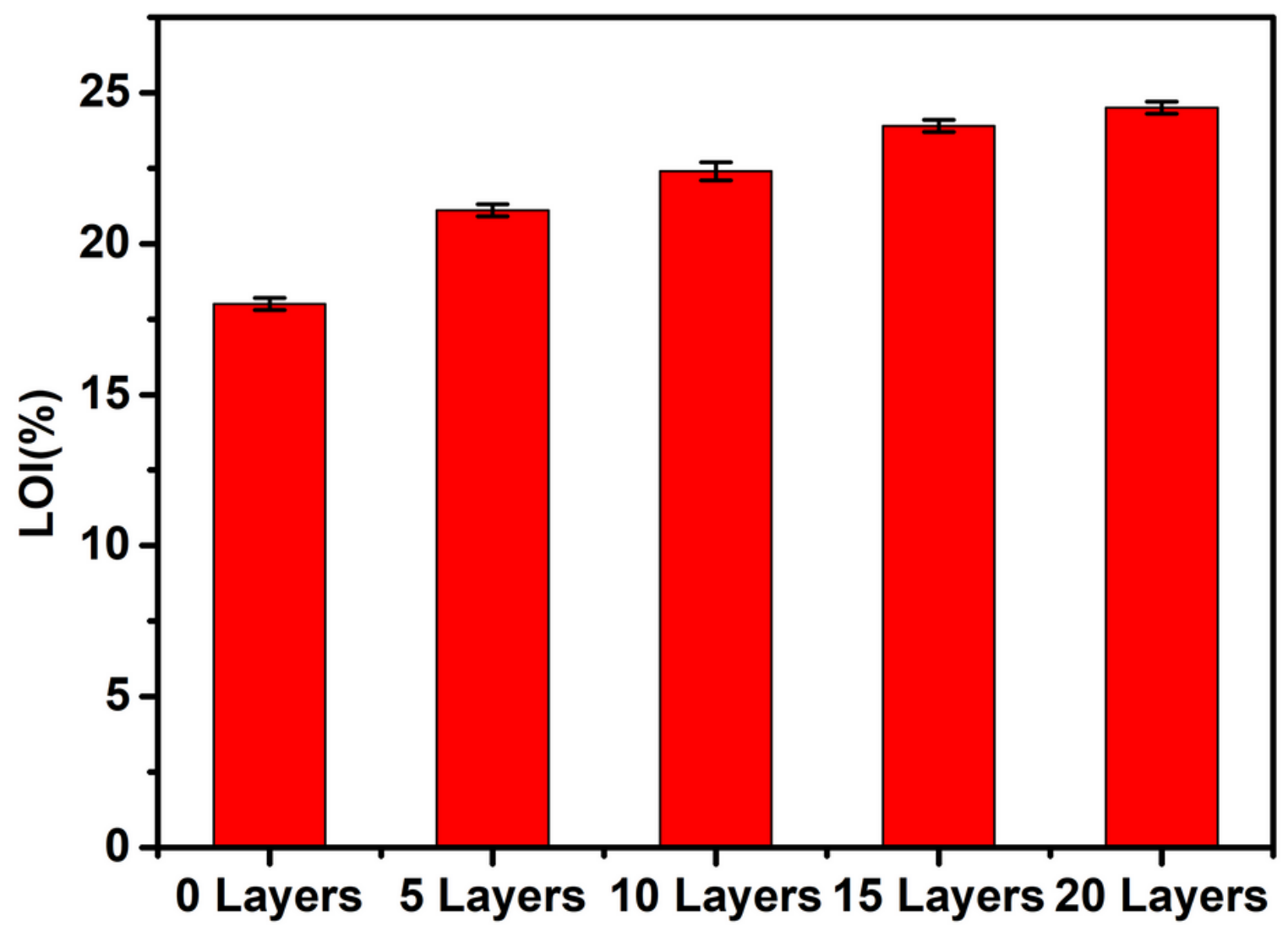

Figure 6

LOI of treated fabric with different layers 

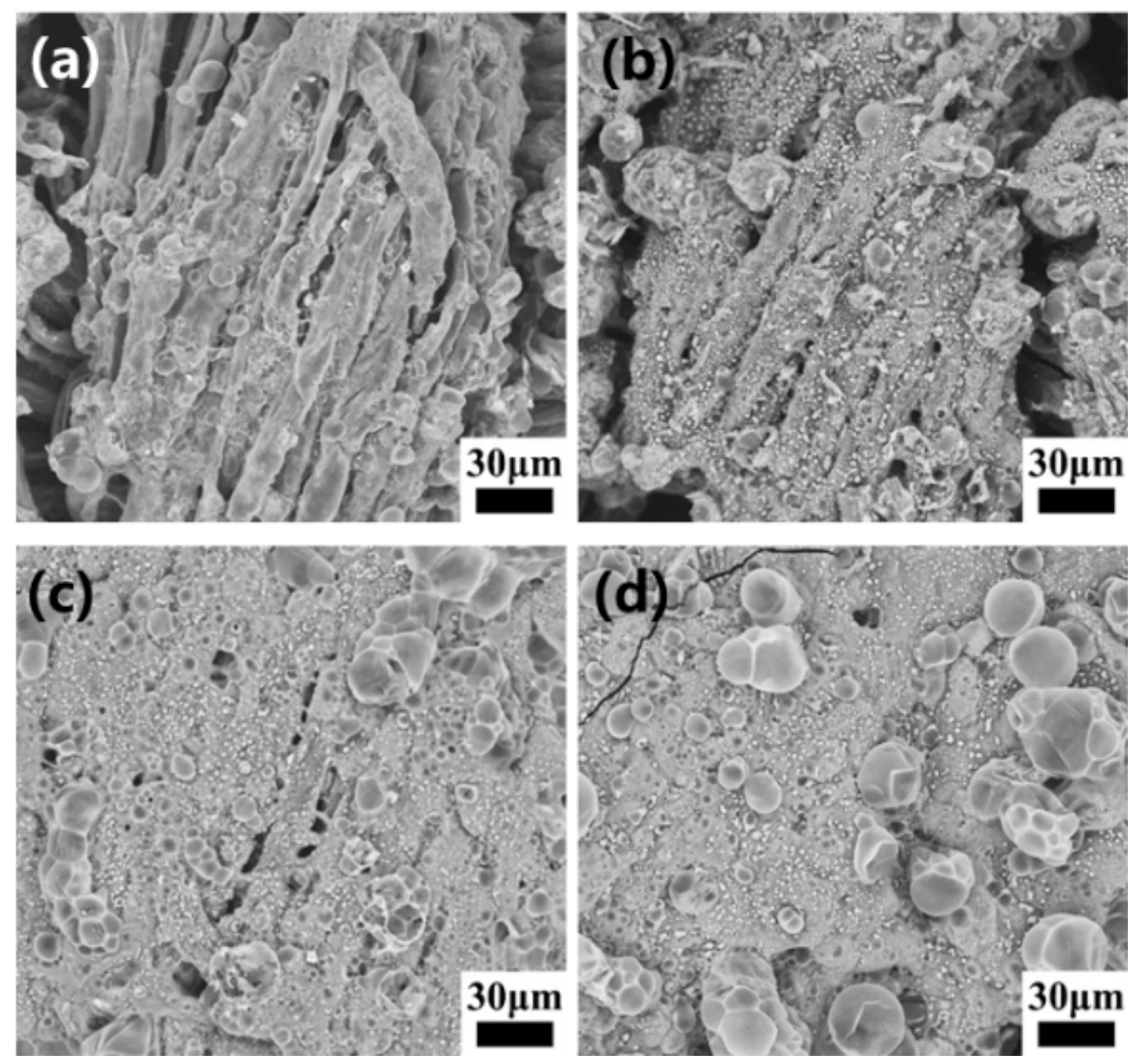

Figure 7

Surface morphology of treated cotton fabrics after burning. (a) SEM of MPCM/APP-5 after burning, (b) MPCM/APP-10 after burning, (c) MPCM/APP-15 after burning, (d) MPCM/APP-20 after burning

(a)

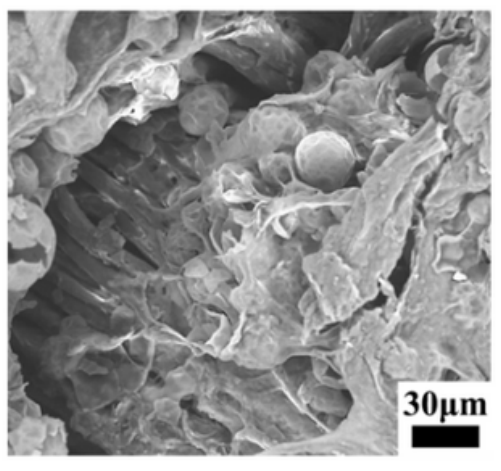

(b)

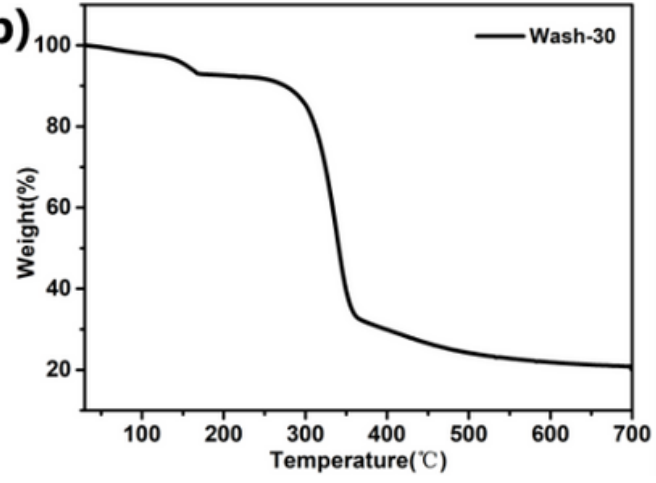

(c)

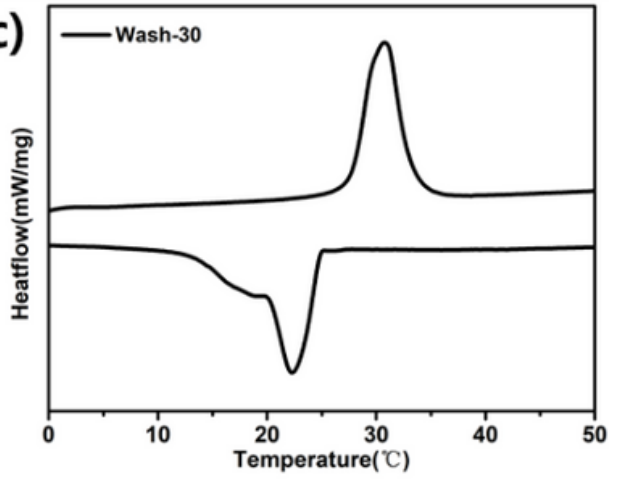

Figure 8

Durability of MPCM/APP-20. (a) SEM image of MPCM/APP-20 after being washed for 30 times; (b) TG curves of curves MPCM/APP-20 after being washed for 30 times; (c) DSC curves of MPCM/APP-20 after 
being washed for 30 times

\section{Supplementary Files}

This is a list of supplementary files associated with this preprint. Click to download.

- SupportingInformation.docx 